\title{
A Case Report of Acute Toxicity of Methotrexate
}

\author{
Dr Anusha Reddy
}

\begin{abstract}
Acute methotrexate toxicity : A case report. Introduction: Skin lesions due to methotrexate toxicity are rare. The majority of cases of cutaneous MTX toxicity have been reported in patients with Psoriasis, exceptionally in patients with Rheumatoid Arthritis (RA). We report a case of $R A$ who had acute severe cutaneous MTX toxicity and its subsequent management. Case Report: A 20-year-old woman diagnosed with RA, followed up in the Rheumatology department at Era Hospital, Lucknow for six months in 2017. Since early 2017, she was treated with MTX at a dose of $10 \mathrm{mg}$ once a week orally. A detailed drug history revealed that the patient had accidently taken MTX $7.5 \mathrm{mg}$ twice daily in the preceding 2 weeks of her presentation. She was additionally on treatment with Sulfasalazine, Naproxen and Hydroxychloroquine. She clinically presented with generalized cutaneous and mucosal ulcerations with thick haemorrhagic crusts. Laboratory parameters revealed Serum MTX level $0.3 \mathrm{~mol} / \mathrm{l}, \mathrm{Hb} 3.1 \mathrm{gm} / \mathrm{dl}$, WBC 1500/ cu.mm, Platelet count 20,000/cu.mm (Pancytopenia) and the presence of occult blood on stool microscopy. Conclusion: A clinical diagnosis of acute severe cutaneous MTX toxicity was suspected. The patient started to recover over the next 10 days following MTX withdrawal and treatment with Injection Leucovorin, Filgastrim, Meropenem, Piperacillin, Urine alkalinizers and Blood Transfusion. Although MTX is an option of great therapeutic value for RA, Rheumatologists and Dermatologists need to be alert concerning the possibility of cutaneous adverse events associated with MTX therapy.
\end{abstract}

Keywords: Rheumatoid arthritis, Methotrexate, Toxicity

\section{Introduction}

Methotrexate (MTX) is a folic acid antagonist which reduces the level of tetrahydrofolate in cells by inhibiting dihidrofolate reductase enzyme. Through this mechanism, it blocks the synthesis of timidilate required for deoxyribonucleic acid (DNA).[1] Low doses of MTX are used in the treatment ofinflammatory diseases such as rheumatoid arthritis(RA). It is the first choice among most physicians since it has a low activity/toxicity ratio and is considered an essential drug [2]. There commended weekly dose is $5-25 \mathrm{mg}$ in RA. Toxicity may occur in low-dose MTX; however, it is usually related to a long duration of treatment and high doses.[3]Bone myelosuppression, pancytopenia, agranulocytosis, inflammation and necrotic changes in mucous tissues, liver cell necrosis and hepatic cirrhosis, pulmonaryfibrosis, disorders of kidney function, vasculitis and skin lesions are some side effects that may occur during the use of MTX.[1]. When MTX is used in high doses, calciumfolinate is the recommended rescue therapy. We report a patient with RA who had been given MTX in excess of the recommended dose. The patient was admitted to the emergency unit with oral ulcers, diarrhea, vomiting, fever and developed febrile neutropenia

\section{Case Report}

A 52-year-old female patient with a diagnosis of RA for two years was admitted to our hospital. Her complaints were ongoing nausea and vomiting for two days, diarrhea with blood and mucus, abdominal pain and fever. Right upper quadrant tenderness and painful ulcers on the oral mucosa was detected on physical examination.Fever was $39^{\circ} \mathrm{C}$ and arterial blood pressure was $140 / 90 \mathrm{mmHg}$. She was treated with MTX at a dose of $10 \mathrm{mg}$ once a week orally A detailed drug history revealed that the patent had accidently taken MTX $7.5 \mathrm{mg}$ twice daily in the preceding 2 weeks ofher presentaton. She was additionally on treatment with Sulfasalazine, Naproxen and Hydroxychloroquine. pr Laboratory parameters revealed, $\mathrm{Hb} 7.1 \mathrm{gm} / \mathrm{dl}$, WBC 1500/cu.mm, Platelet count measured 20,000/cu.mm
(Pancytopenia) C-reactive protein $107 \mathrm{mg} / \mathrm{l}$,urea $58 \mathrm{mg} / \mathrm{dl}$, creatinine $1.6 \mathrm{mg} / \mathrm{dl}$, erythrocyte sedimentation rate 48 $\mathrm{mm} / \mathrm{h}$, ALT $450 \mathrm{U} / \mathrm{L}$, AST $687 \mathrm{U} / \mathrm{L}$. Plenty of leukocytes and erythrocytes were detected on urine analysis and the presence of occult blood on stool microscopy. We could not measure theblood levels of MTX because of insufficient laboratory conditions in our hospital.

However, the patient had received approximately more than the recommended dose of MTX, and her complaints and blood tests indicated MTX intoxication. For treatment, 15 $\mathrm{mg}$ calcium folinate in 5\%dextrose solution was intravenously infused four times a day for five days. The high fever was thought to be associated with neutropenia and broad-spectrum antibiotic was given Meropenem, Piperacillin, Urine alkalinizers and Blood Transfusion. The diarrhesa, vomiting and oral ulcer disappeared and on the 5th day of calcium folinate treatment, blood test results and clinical findings had returned to normal levels. The treatment of RA of the patient was revised follows: MTX 10 $\mathrm{mg} /$ week, folic acid $5 \mathrm{mg} / \mathrm{week}$, prednisolone $4 \mathrm{mg} /$ day and salazopyrine $2 \mathrm{~g} / \mathrm{day}$, and she was discharged from hospital. No complaint was detected during follow up examination one month late

\section{Discussion}

Methotrexate is an antimetabolite which impairs DNA synthesis by competitively inhibiting folic acid metabolism.[4] It is difficult not to mention the importance of MTX in the current treatment of rheumatic diseases especially RA. It has been used in cancer treatment due to its antiproliferative effect for 50 years and as a diseasemodifying drug in the treatment of RA for 20 years. After the start of treatment, it shows its effect within 3-6 weeks and is usually well tolerated.

Methotrexate toxicity is often dose-dependent. Bone marrow toxicity is one of the most serious side effects, and this may occur even at low doses. Usually, MTX treatments start with low doses to prevent toxicity and these can be increased until desired clinical effects are obtained. Despite a lack of 
clear evidence about lung toxicity of MTX, a chest X-ray is usually recommended before starting MTX treatment. Mucocutaneous side effects may start with mild oral ulcers and progress to serious esophageal, bladder and vaginal ulcers. Liver toxicity is seen less with drug use of less than once a week. Flu-like symptoms such as fever, chills, and muscle pain may occur during MTX treatment.[5] In a 60 month long-term follow-up of 420 RA patients treated with MTX, haematological toxicity occurred in 10 patients (2.4\%) (6 leukopenia, 3 thrombocytopenia and 1 pancytopenia). [3] In another study, 284 RA patients treated with MTX were followed up for a mean of 33.2 months.[6] In this study 14patients (4.9\%) had gastrointestinal side effects, nine patients $(3.1 \%)$ had increased liver enzymes, six patients $(2.1 \%)$ had interstitial pneumonia and four patients (1.4\%) developed pancytopenia. Nadir and Şencan [5] have reported a case of febrile neutropenia and pancytopenia that developed during MTX treatment $(7.5 \mathrm{mg} /$ week, for 3 years). In our case the recommended dose was $10 \mathrm{mg} /$ week, but patient had taken $7.5 \mathrm{mg}$ twice weekly dose. Moisaet al.[1] reported four fatal cases due to liver necrosis, pancytopenia and mucositis during the use of high-dose MTX and emphasized that physicians must be aware of possible fatal side effects of MTX. A case of acute renal failure during MTX treatment $(3 \mathrm{~g} / \mathrm{m} 2)$ of cerebral lymphoma and its successful treatment with leucovorin and thymidine has been reported.[7]

In the present case, positive clinical and laboratory effects of calcium folinate emerged by the third day of treatment. Our case supports the use of calcium folinate as an effective treatment option for MTX toxicity

\section{Conclusion}

Although MTX is an option of great therapeutic value for RA, Physicians need to be alert concerning the possibility of adverse events associated with MTX therapy. patients should be adequately informed about the possible toxic effects of MTX when it is prescribed because many patients cannot communicate with their physicians after that time. Physicians should be accessible for patients. Under positive conditions, this drug can be effectively used, and possible side effects and economic losses may be prevented

\section{References}

[1] Moisa A, Fritz P, Benz D, Wehner HD. Iatrogenicallyrelated, fatal methotrexate intoxication: a series of four cases. Forensic SciInt2006;156:154-7.

[2] Seçkin Ü, Borman P, Bodur H, Han Ö, Gön B. Romatoidartritlibirolgudametotreksat tedavisinibağlıhızlanmışnodülgelişimi. Turk J Rheumatol2000;15:137-40.

[3] Ohosone Y, Okano Y, Kameda H, Hama N, Matsumura M, Nojima T, et al. Toxicity of low-dose methotrexate in rheumatoid arthritis-clinical characteristics in patients with MTXinduced pancytopenia and interstitial pneumonitis. Ryumachi1997; 37:16-23. [Abstract]

[4] Abu-Shakra M, Nicol P, Urowitz MB. Accelerated nodulosis, pleural effusion, and pericardial tamponade during methotrexate therapy. J Rheumatol1994;21:934-7.
[5] Nadir

I,

Şencan

M.

Düşükdozmetotreksat'abağlıpansitopenigelişenromatoida rtrit olgusu. C. Ü. Tıp FakültesiDergisi2002;24:81-2

[6] Nakazaki S, Murayama T, Katoh S. Cytopenia associated with low dose pulse methotrexate in the treatment of rheumatoid arthritis. Ryumachi2001;41:929-37. [Abstract]

[7] van den Bongard HJ, Mathĵt RA, Boogerd W, SchornagelJH, Soesan M, Schellens JH, et al. Successful rescue with leucovorin and thymidine in a patient with highdose methotrexate induced acute renal failure. Cancer ChemotherPharmacol2001;47:537-4 